\title{
Teaching Technical Communication to Engineering Students at Scale
}

\author{
Sunny Bains \\ University College London \\ sunny.bains@ucl.ac.uk
}

\begin{abstract}
In engineering departments, technical communication is often taught by non-specialist academics on an ad-hoc basis. This paper shows the benefits - to students, employers, and universities - of taking a more programmatic view of such teaching. Specifically, we show how more thoughtful design of assignments and the rubrics and markers for assessing these can allow a single technical communication professional to effectively teach 1000 students or more.
\end{abstract}

Index Terms - Peer feedback, rubrics, marking consistency, assignment design, postgraduate teaching assistant, dual-use assignment, formative feedback, summative feedback, technical presentation, technical writing.

\section{INTRODUCTION}

Employers complain that engineering graduates can't communicate [1]-[3]. In the British and many other higher-education systems, engineering students (and academics) are selected for their skills in maths and science: not writing or presentation [4]. In addition, engineering students they do relatively little writing at high school post-16 because they are focussed on science, maths, and computing. This means that, when they get to university, even those who were once good at (for instance) writing are out of practice and, worse, have been led to believe that it is not part of technical life. Further, many engineering students remember their high-school instruction in composition as dominated by aesthetic considerations rather than pragmatic ones. Subjective and unhelpful feedback will likely have exacerbated those concerns.

The practical problems of teaching young engineering students, caused by this cultural issue, become obvious very quickly. Many undergraduates resist anything they perceived as non-technical. Over a period of more than a decade, we took an informal poll of students on the first day of transferable skills classes: one third freely admitted they chose an engineering degree in the hope that they would never have to write again.
In 2013 our engineering faculty decided to overhaul its undergraduate program to make it more practice-based, and at the same time started to develop a professional skills module and a technical communication strand that taught to more than 1000 students across two academic years and seven different departments. Based on almost five years of experimentation and optimization, we have determined that students have three primary concerns: workload, relevance, and feedback. Though the workload issue is self-explanatory, it is worthwhile slightly unpacking relevance and feedback. Specifically, students will see an assignment as being relevant if it is technically interesting to them and/or it is tightly connected to a specific engineering assignment they have been given and/or it is put in the context of some professional role they may have in the future. Feedback is deemed acceptable if it is clear, consistent (fair), timely, and expected (i.e. criteria for success are communicated as part of the assignment description).

Further, our work with five successive cohorts has determined that - to meet these student concerns within the resource constraints of a publicly-funded research university - there are five critical issues for ensuring the success. If all the individual issues are well-implemented then they feed into one another in a virtuous circle. If not, each can corrode the effectiveness of the others.

First, to encourage them to take their writing more seriously and minimize workload communication assignments must have a technical basis. Second, the feedback they received must to systematic, pragmatic, and understandable: it cannot be seen as being (too) subjective or aesthetic, and it should be marked using a clear rubric. Third, markers must be carefully trained so that this feedback can be given consistently. In an international institution with diverse levels of skills among the postgraduate students who are expected to mark, this is not a trivial task. Fourth, in order to get sufficient feedback to allow development over time and make sure the criteria for success are reinforced in the minds of the students whilst satisfying their need for quick feedback, peer-review, if well used, can be an extremely powerful (and efficient) tool. Finally, a careful balance between 
formative and summative assessment must be struck in order to ensure that students see the entire process as fair.

\section{DUAL-USE ASSIGNMENTS}

Some of those designing engineering modules and programs believe that simply including communicationbased deliverables in the curriculum automatically teaches students to communicate. This is not true. Careful design is necessary to ensure both that the sets of learning objectives are met. Clear technical relevance to the subject is crucial for student acceptance, but the assignment must also be designed in such a way that students will engage with and practice the communication skills that they are being taught. In our program, these skills include technical argument, explanation to a given audience, writing, presentation, and visualisation. Fuller details about the philosophy behind and specific details of the curriculum are available here [5].

An example of a poor choice of assignment is a lab report which, for many engineering departments (including at our university), is one of the few individually written assignments routinely done by students before their final-year or capstone project reports. Lab reports are poor vehicles for teaching writing for many reasons: they are generally written for a technical audience, giving students little chance to think about explanation; they are too tightly structured, giving little chance to think about structure; and - especially for more junior students - they tend to too-closely summarize the documentation given for the experiment, with little variation in approach except in the results and discussion sections. Apart from anything else, this latter property encourages plagiarism, discourages critical thinking, and makes the process of writing seem futile and unproductive. Further, there is generally little need to make a clear argument in a lab report because it is just seen as the documentation of an experiment meaning that the assignment cannot meet most of our learning objectives.

To teach our students how to argue for the utility of a specific approach (as in a research proposal, a technical paper, even a business pitch) we needed to look for other options. Two of these - the executive summary and the emerging technology report - have proven highly successful and adaptable to many different situations, so we will describe these further here.

In the executive summary, students are given a paper to read (usually a 6-10-page review) on a topic that is specifically relevant to the curriculum of one of their technical courses and, ideally, that needs to be read so that students can perform a specific experiment or project. In advance of that project, students are asked to write an executive summary of the paper that answers a question pertinent to the subject at hand. For instance, in advance of a project on biofuels, students were asked to read a paper discussing the engineering and economic prospects of various biofuels in different parts of the world and then asked to write a summary explaining which biofuels would be most viable in the UK. The report is written for an executive who is not expert in the field being covered (more on this in the section on marking and training) and who has forgotten the whole purpose of assigning the report (making the introductory sections critical).

Because every student is answering the same question, the paper can be marked both based on identifying the correct technical points. In addition, they can be marked on their ability to be able to achieve specific goals in the writing process, from making a clear argument to using paragraphs to avoiding repetition.

Where a class has diverse interests, making a piece on a single topic inappropriate, the executive summary can be attached to a personal project (e.g. a capstone undergraduate project, $\mathrm{MSc}$ dissertation, or $\mathrm{PhD}$ thesis). Again, the student is told to write for an audience not expert in their field. In the peer-review marking we use for such assignments, not only does this offer students a good chance to rehearse the argument for their thesis, it also forces them to think about writing for a non-expert audience.

The emerging technologies report is an ideal assignment for very early students in that it includes elements of research and analysis as well as communication. The student is asked to choose a topic that they are very interested in (an important criterion). Within the general area they pick a particular instance of an emerging technology and argue whether it is likely to succeed in whatever application it is intended for. This requires that students consider the application itself, what criteria must be met to ensure success, and competing technologies both in use and in development. Again, the fact that the assignment is an argument and the choice of audience (with a general technical background, not specialist within the field) make this ideal for teaching the basics of technical communication.

Both of these assignments can be further augmented by requiring students to produce an original figure (one that they create themselves and is not a direct copy of any other) in their reports. This can be particularly productive if, for instance, they are urged to take a figure meant for a very technical audience and to simplify it for a less technical group.

With creativity, many other assignments can be devised for different modules with different learning objectives on the technical side. However, these will only succeed if they are also well-designed from the communication side.

\section{MARKING RUBRICS AND FEEDBACK}

Rubrics are well known to be critical for conveying learning objectives to both students and markers [6]-[8]. 
As discussed previously, to make communication feel compatible with the culture of engineering, to aid both the writing, and marking processes, and to improve the quality of feedback, we have developed very detailed rubrics. The typical mark sheet contains about 30 criteria, all simple, pragmatic and linked to clear learning goals. Most are allocated on a yes-or-no basis (see examples below)

\section{EXPLANATION}

a) Text pitched at an interdisciplinary audience?

b) Individual concepts clearly explained in a step-by-step fashion?

c) Jargon terms ALL defined on first use?

d) Acronyms ALL defined on first use?

e) Are technical terms used accurately and consistently?

\section{INTRODUCTION}

a) Introduces general topic and context?

b) Prepares reader for what's coming?

c) Logical structure that moves from general to specific?

\section{PARAGRAPHS}

a) Topic Sentences

b) Topic Sentence Test

c) Coherence

d) Length

or, similarly, on an absent/insufficient basis:

\section{TECHNICAL ARGUMENT}

a) Vision

b) Status Quo

c) Technical Problem

d) Competing Solutions

e) New Solution

f) Obstacles

g) Discussion/Future/Prognosis

h) Order of Argument Elements

The marking criteria and long-form guidance are, crucially, given to the students in advance of submission, so that they can learn about the criteria while they try to meet them. Also, because they are so detailed, they act along with accompanying explanations on the paper about exactly where the various marks were lost - as excellent feedback for the student. Though we generally use these criteria for technical reports, we generally find the approach works well for any form of communication.

\section{TRAINING POSTGRADUATE MARKERS}

As well as being excellent teaching tools and vehicles for feedback, these rubrics can be used to allow consistency in situations (such as ours) where there are numerous markers. We have to mark more than 1000 papers per year (sometimes significantly more than that) as well as hundreds of presentations. Like many universities, we are able to achieve this scale by making extensive use of post-graduate teaching assistants. This is a common tactic, but often the quality of the teaching assistants is insufficient. One problem is that, in our research-based university, there is minority of nativeEnglish speakers doing $\mathrm{PhDs}$, and - though generally better than their undergraduate counterparts - few had genuinely good communication skills.

We developed a program that involves up to 20 hours of training (12 hours training plus a further $8 \mathrm{~h}$ of homework) per postgraduate teaching assistant (PGTA). After some formal instruction (a $2 \mathrm{~h}$ mass workshop and at-home reading) each prospective PGTA takes five $2 \mathrm{~h}$ classes in small groups (eight or fewer). Because our PGTAs are recruited from across both physical sciences and engineering, the diversity of the workshop groups helps to ensure that students are forced to think about the audience in advance and explain topics without jargon.

The first of the two writing workshops focuses on the technical argument, while the second focuses on other writing issues: particularly weighting of sections, paragraph structure, repetition, jargon, and so on. The third workshop is a marking exercise. The PGTAs are given a piece to mark and then we discuss in class why we marked it in the way we did. This gets them familiar with the marking criteria and acts as a first calibration step (we have a further calibration meeting for each specific assignment to be marked).

The latter two workshops focus on presentation skills. They are asked to prepare a 5-minute presentation on the same topic as the writing class, and for the same audience. The presentation is videoed so that, after a short discussion, it can be watched back by the entire class (including the speaker) for marking purposes. Each postgraduate only gives a presentation in one of the two classes they attend. However, they must mark all the presentations and participate in giving feedback to their classmates. This training helps them not only to improve their own presentation and critical skills, but also to run identical classes for the undergraduate students.

An important aspect of the training is that it is possible to fail it. Although the techniques used are generally effective, some students do not get through because they lack the motivation (they do not believe communication is sufficiently worth their time), the temperament (cannot accept criticism), or the aptitude (despite effort, they make little progress) for the work. Students in all three groups generally drop out before being failed, but it is important to have a clear standard in place.

Using this intensive program, we train approximately 20 new PGTAs every year. In addition, a further 20-30 are refreshed and updated on any assessment/criteria changes (they attend the initial mass workshop, one additional writing-marking and one presentation class each year). This nominal team of 40-50 gives us sufficient manpower to mark the large number of papers we have to 
process (generally 300 to 500 at a time) within the time we are given two do it (no more than four weeks, including second marking).

Before moving on to the next topic, it is important to note how critical the first two steps - the design of the dual-use of assignments and the pragmatic, highly spelled-out rubric - are critical to the success of the training of the PGTAs. Because these postgraduates, despite their training, are still not experts, it is critical that they have a very clear, non-subjective rubric to help them mark consistently. Although we also do second marking (markers check and correct each other's work) and moderation (for presentation sessions, because only one marker is present), these would not be enough to give sufficient consistency without the rubrics being in place. Further, without the design of assignments aimed at markers aimed at non-specialist backgrounds, we would not be able have biochemical engineers marking the work of mechanical engineers and vice versa.

Note that this last point may not seem like a relevant constraint to those working within a single engineering discipline (i.e. if those training mechanical engineering PGTAs to mark mechanical engineering undergraduates. However, the cross-disciplinary audience is more challenging for students than a more homogenous one, as well as being significantly more authentic to professional situations. This, on its own, makes it a better design choice.

\section{PEER-MARKING}

Communication skills take several practice-criticismfeedback loops to acquire. In general, our engineering students will not write unless they get marks for it. Marks means marking, which has to be done quickly enough to provide feedback before the next assignment. Even with our team of teaching assistants and rubrics, it is not possible to have every paper fully marked by paid staff.

Peer-marking, is an obvious solution to the problem: as it has both practical and educational benefits[9]. Not only does it supply students with a focus-group to test out and get feedback on their work, but it helps students to understand the communication learning objectives being taught by using related criteria to judge others. To make this work, each set of peer markers, with their diverse opinions, must be a legitimate part of the audience set in the assignment design and the questions they are asked must relate to their own understanding rather than any objective truth about the submission being reviewed. In other words, they should legitimately be able to answer the question: How well does this communicate to me?

However, trying to implement this in practice is more difficult than it might seem in theory. Many of the issues relate to student acceptance: without careful explanation, students may feel that they are doing their teachers' work, that their peers are not qualified to mark them, and that inconsistency among their peer markers shows that the marking process is flawed.

Our process evolved over five years and more than a dozen peer-marking assignments. By combining several different steps, we have now reduced the number of complaints about these assignments to almost zero. First, it's extremely important that the students understand that they are learning as much from doing the peer marking as they are from receiving it. Not only does the literature show this, but our students verified it in a large poll we conducted in 2015 (note that this was before we optimized our processes). We anonymously surveyed our 725 first year students that year (these were the majority of the students doing peer-marked assignments). 405 responded. Of these, 59\% said they learned Quite a bit or A lot from doing the reviewing. Similarly, 50\% said they learned Quite a bit or $A$ lot from reading their reviews. Those who said they learned Very little from either were less than $10 \%$. This shows the approach was already producing dividends for the students.

The design of the rubric is of, course, critical here [10]-[12]. For these assignments, we have a much smaller number of questions. Four levels of success are possible, and the criterial for each level is spelled out in detail. It is made very clear whether the mark is given either objectively (e.g. use of topic sentences) or subjectively (e.g. explanation) and a comment (not a free comment, but a guided one) is required to justify the marks given. Also, to emphasize that the peer markers represent a focus group rather than an authoritative marker, we include opportunities for the marker to justify their marks in terms of their own technical background. For instance, a mechanical engineer may not understand why their marker thinks the term Newton's second law of thermodynamics is jargon. However, if the marker is encouraged to explain that they have no physics training (only chemistry, biology, and maths) then the student is more likely to accept the given mark as valid. See example question from the rubric below.

\section{Explanation}

Think about how well you understood the technical mechanisms, processes, or systems the author was explaining. You should be able to follow the report without having to look up jargon words or technical concepts you don't know.

a) Grade the report appropriately using the following scale:

3/3 Excellent - The report was at just the right technical level for you throughout. 2/3 Good - The report was generally good but either:

i A few jargon words crept in that you had to look up.

ii The report felt just a little too simple and didn't get quite far enough into the technical detail as you would have liked. 
iii Both of the above were true, but in different sections.

1/3 Needed work - The report was OK, but:

i There was quite a bit of jargon that you didn't understand and was not explained.

ii The report was significantly oversimplified and the explanations were very shallow.

iii Both of the above were true, but in different sections

0/3 Insufficient - The entire article seemed aimed either at someone with no technical background or at someone with deep knowledge of the discipline, or a mixture of the two.

b) In the comments box, if you thought the report was: Excellent, give an example of a jargon word that was well defined (and include the definition).

Good, Needed Work, or Insufficient, give an example of a jargon word that was badly defined or not defined at all. Say what discipline of engineering you are studying so that the author can get a better understanding of why you might not have understood this term.

Another measure that aids acceptance is a robust appeals procedure so that students who felt that they had been unfairly marked had means of redress. In our process, we make clear that people may only appeal against those who have marked in a negligent or abusive way. Negligence might include not including proper justification of marks, i.e. not fully answering part (b) of each question. Abuse would include making comments and value judgements about the writer rather than about the writing. For instance, it would be fine to say that a phrase was left undefined, but not that, "the writer couldn't be bothered to even define ..." If a student's appeal is upheld, then their marker does not only lose the marks allocated for that particular review, but for all their peer reviewing in that assignment whether there was an appeal or not. Knowing that they are subject to this process helps the students take the work seriously.

\section{Formative Vs. Summative FeEdBACK}

Different groups of students and different assignments require different approaches when it comes to feedback. For instance, we find masters level students fairly mature in their approach. In a peer-marked executive summary assignment, they will readily accept the marking variation they see from their peers, which gives us a lot of flexibility. For undergraduates, particularly in the first year, this is not the case. We have therefore developed a system of using peer-marking for formative (feedbackonly for improvement at the next stage) assessment and PGTA-marking for summative (graded) assessment on different stages of a single large assignment.
This is more difficult than it sounds, in the sense that immature students are much less likely to produce work when no marks are allocated to it (even if formative feedback will help them to improve their final grade). To counter this, we have developed a system where the submissions to the formative assignments are not allocated marks, but performing the peer-review of other works does have marks attached (essentially on an all-ornothing basis). Because the students cannot peer-review others without submitting themselves, this encourages to submit and get feedback without feeling resentful if the feedback they receive is more critical than they feel is deserved.

By using the peer-feedback in the formative stages of the assignment (in the first year this is an emerging technologies report with a figure), the students go through the practice-feedback loop five times over the course of the year. PGTAs only have to be involved in the summative marking of the final two deliverables: the presentation and final report. Since the peer-review process can be considered an additional instruction/engagement step, we can amplify the learning significantly without using additional resources.

One extra note. The second last deliverable (the presentation) can be considered both formative and summative. In terms of timing and feedback, it takes place early enough for the students to use the feedback to do better in their final report, but it also contributes significantly to their final grade.

\section{DISCUSSION}

One of the critical factors that should be noted here is the interdependency of the different approaches used in the design of this program. Without the appropriate design of the dual-use assignments and rubrics, it is not possible to use PGTAs. Then, if PGTAs are to be used, they must be trained. Without the use of PGTAs and appropriate design of peer-review assignments and rubrics, it is not possible to give the students enough practice and feedback. Without a balance of formative and summative assessment strategies, it is not possible to get student acceptance of use of peer review.

It should be noted that the work described here comes from a review of theory and application in practice, but not from experiment in the traditional sense of doing social sciences research. As a university with students paying for tuition, it is not ethical for us to experiment on them in a conventional way (e.g. using a test and control group). Our remit is to teach. Nevertheless, there are feedback signals inherent in teaching in exactly the same way as there are in any other system. If our teaching, documentation, or rubrics are unclear, then - with a firstyear cohort of approximately 500 doing the same work we will get a certain number of queries. As we optimize, this number goes down. Though we do not track the exact 
numbers, since the inception of the current first year program, the number of queries has dropped from the hundreds down to the low tens. Likewise, if our assessment program appears unfair, irrelevant, or inconsistent to students, students will complain. Over the course of five years, again, the number of complaints has dropped from dozens to a handful.

In terms of the quality of learning, we can see this reflected in the quality of the final pieces of work submitted. Though the grades do not necessarily change (because they are connected to the design and weighting of the rubrics, which is constantly being optimized and updated) it is apparent what is getting through to students - and what is not - by looking at their work. Markers have seen an improvement in this learning through the iterations.

Note that we do 'take the temperature' of students via questionnaires at various points and use this as feedback to improve further. However, these cannot be considered real experiments, only attempts to achieve stakeholderdriven design.

There is one exception to this, however. In 2014, an error occurred with Moodle Workshop (which we use to implement the peer-review assignments). Instead of each student being allocated four other submissions to mark, they were allocated between three and six submissions. As it was too late to fix the problem before it came to light, we used the opportunity to survey the students afterwards, asking how many they had been allocated, how many they had received and how many they thought would be ideal. Interestingly, they decided that four allocations (which was already our target number) was ideal. Although we don't know for sure why they chose this number, we believe this is because three is the minimum number that can be considered a 'focus group'. Since some people would fail to do their peer marking, the number of reviews some would receive would drop to an unsatisfactory two. Thus, four seems the obvious choice to optimize both feedback and workload satisfaction.

\section{CONCLUSION}

With just one full-time member of teaching staff, in one year our technical communications teaching team is able to: train more than 20 postgraduate teaching assistants and refresh a further 20-30; instruct more than 1000 engineering students; video, discuss, and grade more than 500 technical presentations; mark more than 1000 technical reports, and supervise the marking of almost 2000 peer-reviewed submissions. This is only possible through a carefully-crafted program that optimizes assignment design, rubric, and marker training with the learning objectives within the communication curriculum, incorporating peer-reviewed formative steps to increase student engagement and practice. By understanding the interdependencies between these different elements and systematically optimizing over time, technical communication teaching can be made extremely resourceefficient while supplying students with high-quality, relevant, timely, and consistent feedback.

\section{REFERENCES}

[1] M. J. Riemer, "Communication Skills for the 21st Century,” Glob. Journal. Eng. Educ., 2007.

[2] J. Denham, "Graduates unprepared for employment Many graduates are not prepared for the working," Indep., no. 13 September, 2013.

[3] F. Levy and C. Cannon, "The Bloomberg job skills report 2016: What recruiters want," Bloom. Businessweek, 2016.

[4] M. Boylan, Characteristics of First-Time Freshmen in 4-Year Institutions Intending to Major in Engineering and Computer Science; an analysis of survey data collected by the Higher Education Research Institute ( HERI) Introductory Note The central focus of this pap. National Academy of Engineering.

[5] S. Bains, Explaining the Future: How to Research, Analyze, and Report on Emerging Technologies. Oxford University Press, 2019.

[6] H. G. Andrade, "Using Rubrics to Promote Thinking and Learning," vol. 57, no. 5, pp. 13-18, 2000.

[7] D. Allen and K. Tanner, "Rubrics: Tools for making learning goals and evaluation criteria explicit for both teachers and learners," CBE Life Sciences Education. 2006.

[8] L. B. Nilson, Teaching at its best: A research-based resource for college instructors. 2010.

[9] R. M. Felder, D. R. Woods, J. E. Stice, and A. Rugarcia, "The future of engineering education: Part 2. Teaching methods that work," Chemical Engineering Education. 2000.

[10] P. Orsmond, S. Merry, and K. Reiling, "The importance of marking criteria in the use of peer assessment," Assess. Eval. High. Educ., vol. 21, no. 3, pp. 240-250, 1996.

[11] L. B. Nilson, "Helping students help each other: Making peer feedback more valuable," Towar. Best Acad., vol. 14, no. 5, pp. 1-5, 1999.

[12] S. Bloxham and A. West, "Understanding the rules of the game: Marking peer assessment as a medium for developing students' conceptions of assessment," Assess. Eval. High. Educ., vol. 29, no. 6, pp. 721-733, 2004.

\section{ABOUt THE AUTHOR}

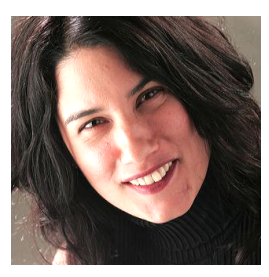

Sunny Bains is a Principal Teaching Fellow at University College London, in the Department of Biochemical Engineering, author of Explaining the Future: How to Research, Analyze, and Report on Emerging Technologies, and Editorial Director of Engineering Inspiration http://engins.org. She has two 
decades experience as a technical journalist and editor (for The Economist, New Scientists, Science, Wired, EE Times, Laser Focus World, and many others), and another two teaching at the University of California at Berkeley, Imperial College London, and UCL. She has a BSc in Physics (Queen Mary, University of London, 1990), an MS in Journalism (Boston University, 1994), and a PhD on Physical Computation and Embodied Artificial Intelligence (Open University, 2005). She teaches research, analysis and communication skills to students at various levels across engineering and the physical sciences. 